\title{
Plasma Transfusion and Lung Injury in the Pediatric Intensive Care Unit
}

\section{Robert A. Niebler ${ }^{1 *}$, Melissa Christensen ${ }^{2}$ and Jennifer McArthur ${ }^{1}$}

${ }^{1}$ Medical College of Wisconsin, Department of Pediatrics, Division of Critical Care, Milwaukee, Wisconsin, USA

${ }^{2}$ Medical College of Wisconsin, Department of Surgery, Division of Pediatric Surgery, Milwaukee, Wisconsin, USA

\begin{abstract}
Introduction: This study investigated if there was an association between Fresh Frozen Plasma (FFP) transfusion and severity of lung injury as measured by the Oxygenation Index (OI) in a Pediatric Intensive Care Unit (PICU) population.

Methods: This was a retrospective cohort study of 178 patients who had data available to calculate the OI $\left(\mathrm{Ol}=\right.$ mean airway pressure $\left.\times \mathrm{FiO}_{2} \times 100 / \mathrm{P}_{2} \mathrm{O}_{2}\right) .166$ patients were transfused with FFP and 12 control patients with an INR > 1.5 who were not transfused with FFP were included. The OI was calculated at time 0 (prior to transfusion or at time of peak INR in controls); $6 ; 24$; and 48 hours later.
\end{abstract}

Results: Change in the OI was $-0.2 \pm 4.1,0.3 \pm 4.9$, and $0.0 \pm 6.8$ at 6,24 , and 48 hours respectively in the transfused group and $0.3 \pm 0.7,1.5 \pm 5.4$, and $3.3 \pm 9.5$ at 6,24 , and 48 hours respectively in the control group. Multivariate analysis failed to find a significant association between FFP transfusion and a change in the OI.

Conclusion: FFP transfusion was not associated with a change in the severity of lung injury as measured by the OI.

Keywords: Fresh frozen plasma; Transfusion; Acute lung injury; Pediatrics; Blood component transfusion

\section{Introduction}

Transfusion Related Acute Lung Injury (TRALI) is a rare event, estimated at an incidence of 1 in 5000 blood component transfusions [1] and 1 in 7,900 units of Fresh Frozen Plasma (FFP) transfused [2]. An attempt to define the incidence in pediatric populations found one case of TRALI in a population of 305 Pediatric Intensive Care Unit (PICU) patients who received a total of 2509 transfusions [3]. Despite the reported low incidence of TRALI, studies in adult Intensive Care Units (ICU) show a significant association between Acute Lung Injury (ALI) and transfusion with FFP [4,5]. In the pediatric population, a study of patients with pre-existing ALI showed an association between FFP transfusion and increased mortality [6]. These associations have led some to conclude that milder forms of TRALI may exist and transfusion with plasma containing blood products, especially FFP, may result in impairment of lung function in a larger proportion of patients than previously appreciated [7].

The oxygenation index $\left(\mathrm{OI}=\right.$ mean airway pressure $\times \mathrm{FiO}_{2} \times 100 /$ $\mathrm{PaO}_{2}$ ) has been used in the pediatric literature as a means of quantifying the degree of lung injury. The OI can be used to compare patients exposed to different strategies and modes of mechanical ventilation by including the mean airway pressure in its calculation. In a comparison with the more traditional measure of gas exchange, the $\mathrm{P}_{2} \mathrm{O}_{2} / \mathrm{FiO}_{2}$ ratio, the OI has been shown to be a superior predictor of mortality and duration of mechanical ventilation in the pediatric age group [8].

Our study investigates if there is an association between transfusion with FFP and worsening lung function in PICU patients requiring mechanical ventilation. For the purpose of the study, severity of lung injury was measured by the OI.

\section{Materials and Methods}

This is a retrospective cohort study of PICU patients at the Children's Hospital of Wisconsin, a free standing tertiary care children's hospital, between January 2004 and November 2006. After institutional review board approval, charts of all patients who received FFP or had an International Normalized Ratio (INR) of greater than or equal to 1.5 , and had data available to calculate an OI were reviewed. Patients who did not receive FFP were assigned to the control group. Patients who were on cardiopulmonary bypass or extracorporeal membrane oxygenation and patients with an intra-cardiac shunt were excluded as the OI may not be an accurate measure of lung function in these patients.

The OI was calculated at time 0 (prior to transfusion or at time of peak INR in controls), as well as 6,24 , and 48 hours later. The change in OI was defined as the difference between the value at time 0 and subsequent data points. Age, underlying diagnosis, volume of FFP transfusion, types of other blood products transfused, Pediatric Risk of Mortality III Risk of Mortality scores (PRISM 3 ROM), and Central Venous Pressures (CVP) as an indication of circulatory overload were collected as possible confounding variables.

The transfused and control groups were compared using the Mann Whitney test for continuous data and the chi-square test for proportions. To examine the interrelationship between variables, regression tree and stepwise linear regression were used. For the linear regression, interactions were not considered. No adjustment was made for multiple comparisons. The unadjusted p-value is given. In order to compare the change in OI over time within the transfused group the Mann Whitney test for continuous data and the chi-square test for proportions was used with the time 0 data point used for comparison.

*Corresponding author: Robert A. Niebler, 9000 W. Wisconsin Ave., P.O. Box 1997 (MS 681), Milwaukee, WI, USA, 53201-1997, Tel: 414-266-3360; Fax: 414266-3563; E-mail: rniebler@mcw.edu

Received April 02, 2012; Accepted April 25, 2012; Published May 02, 2012

Citation: Niebler RA, Christensen M, McArthur J (2012) Plasma Transfusion and Lung Injury in the Pediatric Intensive Care Unit. J Blood Disord Transfus 3:122. doi:10.4172/2155-9864.1000122

Copyright: (c) 2012 Niebler RA, et al. This is an open-access article distributed under the terms of the Creative Commons Attribution License, which permits unrestricted use, distribution, and reproduction in any medium, provided the original author and source are credited. 
Citation: Niebler RA, Christensen M, McArthur J (2012) Plasma Transfusion and Lung Injury in the Pediatric Intensive Care Unit. J Blood Disord Transfus 3:122. doi:10.4172/2155-9864.1000122

Page 2 of 3

Multivariate analysis of this data was accomplished with a CART analysis. SPSS and SPlus software were used.

\section{Results}

A total of 376 patients had data available to calculate the OI and either received FFP or had an INR greater than 1.5 during the study period. 198 patients were excluded. Patients were excluded because of cardiopulmonary bypass (27), ECMO support (30), and residual intra-cardiac shunt (141) on post-operative echocardiogram. The final study cohort consisted of 178 patients, of which 166 patients received FFP and 12 patients who did not were used as controls. Demographic information and baseline characteristics of the study patients are shown in Table 1

The OI was calculated in all patients at times 0 and 6 hours. In the transfused group, 25 patients at 24 hours and 56 patients at 48 hours did not have sufficient data to calculate the OI. Data was not available secondary to death (5 at 24 hours, 14 at 48 hours), extubation (17 at 24

\begin{tabular}{|c|c|c|c|}
\hline & $\begin{array}{l}\text { Transfused Group } \\
(n=166)\end{array}$ & $\begin{array}{l}\text { Control Group } \\
(n=12)\end{array}$ & $p$-value \\
\hline $\begin{array}{l}\text { Age in years, median } \\
\text { (range) }\end{array}$ & $3.0(0-23)$ & $1.0(0-14)$ & 0.12 \\
\hline Diagnosis (n) & $\begin{array}{l}\text { CT Surgery }(67) \\
\text { Neurosurgery }(41)^{*},{ }^{* *},{ }^{* * *} \\
\text { Trauma }(47)^{*},{ }^{* *} \\
\text { Sepsis }(15)^{* *},{ }^{* * *} \\
\text { Other }(27)\end{array}$ & $\begin{array}{l}\text { CT Surgery (9) } \\
\text { Other (3) }\end{array}$ & $\begin{array}{l}0.03 \\
0.04 \\
0.04 \\
0.60 \\
0.43\end{array}$ \\
\hline $\begin{array}{l}\text { PRISM } 3 \text { ROM, median } \\
\text { (range) }\end{array}$ & $0.08(0.002-0.969)$ & $0.05(0.004-0.947)$ & 0.32 \\
\hline $\begin{array}{l}\text { CVP }(\mathrm{mmHg}), \text { mean } \\
\pm \mathrm{SD}\end{array}$ & $10.1 \pm 5.5$ & $9.8 \pm 5.5$ & 0.65 \\
\hline $\begin{array}{l}\mathrm{OI}\left(\mathrm{cmH}_{2} \mathrm{O} / \mathrm{mmHg}\right) \text { at } \\
\text { time } 0, \text { median (range) }\end{array}$ & $2.67(1.0-42.2)$ & $2.69(1.6-27.8)$ & 0.99 \\
\hline
\end{tabular}

*29 patients with traumatic brain injury included in neurosurgery and trauma groups

**1 patient with traumatic brain injury and pneumonia included in all three groups ***1 patient with meningitis requiring neurosurgical intervention included in trauma and sepsis groups

Table 1: Demographic information for transfused and control groups.

\section{Change in Ol from baseline}

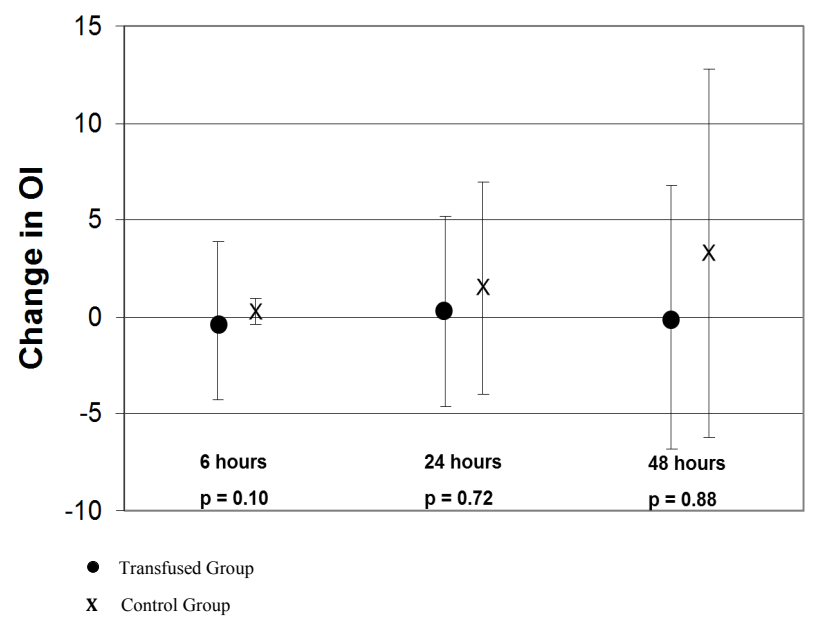

Figure 1: Change in oxygenation index (OI) from baseline: OI at entry - OI at 6 24 , and 48 hours. Values depicted are mean \pm standard deviation. hours, and 39 at 48 hours), no arterial blood gas ( 3 at 24 hours, 2 at 48 hours), and placement on to ECMO (1 at 48 hours). Due to extubation, 4 and 6 patients in the control group did not have data available to calculate the OI at 24 and 48 hours respectively.

Change in the OI at 6,24, and 48 hours in the two groups is depicted in Figure 1. No significant difference $(p>0.05)$ was found comparing the two groups at any time point. Multivariate analysis failed to show any correlation between FFP transfusion and change in the OI. The OI values over time for the transfused group are depicted in Figure 2. No significant difference $(\mathrm{p}>0.05)$ was found comparing the 6,24 , and 48 hour data points to time 0 . In the sub-group analysis, the OI in the transfused patients with sepsis increased by an average of 1.6 from time 0 to 6 hours $(p=0.046)$. No other sub-group showed any significant change in the OI from time 0 values. Regression tree and CART analysis failed to find FFP transfusion or volume of FFP transfusion to be significant factors in determining a change in the OI over time.

\section{Discussion}

Reports in adult ICU populations have associated FFP transfusion with lung injury $[4,5]$. In pediatric patients with pre-existing ALI an increase in mortality was found in patients receiving a transfusion of FFP [6]. These studies have led to conclusions that FFP transfusions may lead to some degree of lung injury in a large proportion of patients, and not just in patients who meet the definition for TRALI.

Our data shows no change in the severity of lung injury as measured by OI following transfusion with FFP. While some patients did worsen as evidenced by an increase in the OI, an equal number improved resulting in no significant change in the sample overall. While prior studies examining this topic have been designed to find an association between lung injury (and outcomes of patients with lung injury) and FFP transfusion, our study is designed to more specifically answer whether a measure of lung injury worsens following FFP transfusion. Each patient in the transfused group functioned as their own control and no difference was seen following FFP administration.

Potential limitations of our study include the retrospective design, limited numbers in the control group, and the use of the OI. The

\section{Oxygenation Index in Transfused Group}

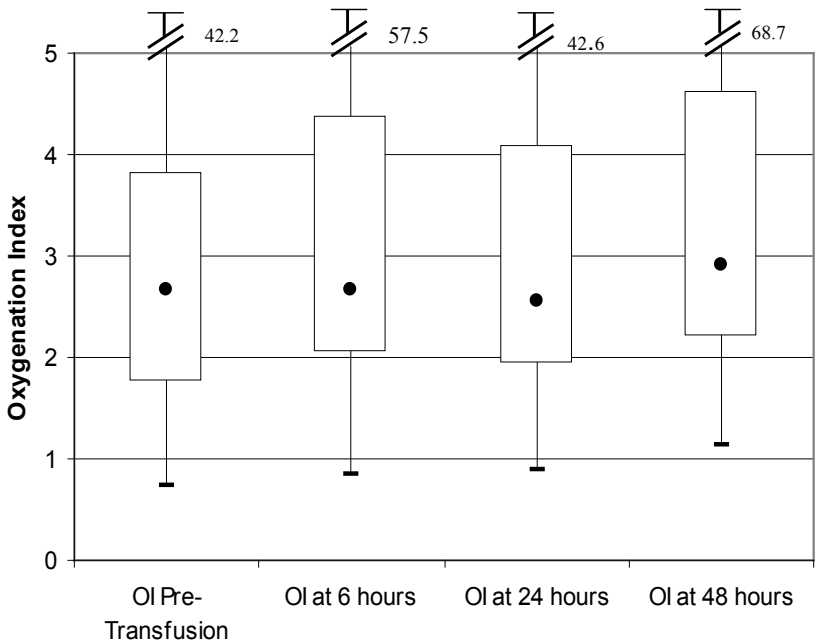

Figure 2: Ol over time in transfused group. Box and whisker plot represents median, quartiles, and range with units of $\mathrm{cmH}_{2} \mathrm{O} / \mathrm{mmHg}$. 
Citation: Niebler RA, Christensen M, McArthur J (2012) Plasma Transfusion and Lung Injury in the Pediatric Intensive Care Unit. J Blood Disord Transfus 3:122. doi:10.4172/2155-9864.1000122

Page 3 of 3

retrospective design resulted in missing data at 24 and 48 hours for a significant number of patients. It is unclear whether data out to 48 hours on the entire cohort would have changed our results. However, the current accepted TRALI definition requires the onset of ALI within 6 hours of the start of a transfusion [9], and our data showed no evidence of worsening lung injury in the entire cohort at 6 hours. In addition, a majority of the patients with missing data at 24 and 48 hours were getting better (extubated or no arterial blood gas available). The OI data in these patients at 24 and 48 hours would likely have shown continued improvement which would have strengthened our overall conclusions.

The number of patients in our control group was small. This is likely secondary to our clinical practice of transfusing FFP for even minor coagulopathies in critically ill patients. A larger control group may have shown improvement in their OI over time, making the relative constant OI in the transfused group a worse outcome. As the other published studies [4-6] on this topic showed a worse outcome in the transfused group our results are still contrary to these reports within our cohort of 166 transfused patients.

The use of the OI as a marker of lung injury resulted in a cohort of intubated patients with arterial lines in situ. This resulted in a relatively ill population which may limit the applicability of our results to a general PICU population. The finding that a "sicker" cohort did not worsen following FFP transfusion is reassuring for the safety of FFP transfusion in PICU populations. Using OI as a marker of lung injury also resulted in a reduction of our cohort size. However, our sample size of 166 transfused patients is comparable to the number of patients studied in other published reports [4-6].

In conclusion, transfusion of FFP did not correlate with a change in the severity of lung injury as measured by the OI in this cohort of patients in the PICU.

\section{Acknowledgments}

We would like to thank Karen Marcdante, MD for her help with manuscript preparation, Melodee Nugent and Pippa Simpson, PhD for their help with statistica analysis, and Michael Lankiewicz, MD for his help with initial study design.

\section{References}

1. Popovsky MA, Moore SB (1985) Diagnostic and pathogenetic considerations in transfusion-related acute lung injury. Transfusion 25: 573-577.

2. Wallis JP, Lubenko A, Wells AW, Chapman CE (2003) Single hospital experience of TRALI. Transfusion 43: 1053-1059.

3. Gauvin F, Lacroix J, Robillard P, Lapointe H, Hume H (2006) Acute transfusion reactions in the pediatric intensive care unit. Transfusion 46: 1899-1908.

4. Dara SI, Rana R, Afessa B, Moore SB, Gajic O (2005) Fresh frozen plasma transfusion in critically ill medical patients with coagulopathy. Crit Care Med 33: $2667-2671$

5. Khan H, Belsher J, Yilmaz M, Afessa B, Winters JL, et al. (2007) Fresh-frozen plasma and platelet transfusions are associated with development of acute lung injury in critically ill medical patients. Chest 131: 1308-1314.

6. Church GD, Matthay MA, Liu K, Milet M, Flori HR (2009) Blood product transfusions and clinical outcomes in pediatric patients with acute lung injury Pediatr Crit Care Med 10: 297-302.

7. Wallis JP (2007) Transfusion-related acute lung injury (TRALI): Presentation, epidemiology and treatment. Intensive Care Med 33: S12-S16.

8. Trachsel D, McCrindle BW, Nakagawa S, Bohn D (2005) Oxygenation index predicts outcome in children with acute hypoxemic respiratory failure. Am J Respir Crit Care Med 172: 206-211.

9. Toy P, Popovsky MA, Abraham E, Ambruso DR, Holness LG, et al. (2005) Transfusion-related acute lung injury: definition and review. Crit Care Med 33 . 721-726. 